\title{
Echocardiographic assessment of the right ventricle in COVID -related acute respiratory syndrome
}

\author{
Chiara Lazzeri $^{1}\left[\right.$ - Manuela Bonizzoli ${ }^{1} \cdot$ Stefano Batacchi $^{1} \cdot$ Adriano Peris $^{1}$
}

Received: 8 June 2020 / Accepted: 4 September 2020 / Published online: 16 September 2020

(c) Società Italiana di Medicina Interna (SIMI) 2020

\begin{abstract}
In patients with the novel coronavirus (COVID-19) infection, the echocardiographic assessment of the right ventricle (RV) represents a pivotal element in the understanding of current disease status and in monitoring disease progression. The present manuscript is aimed at specifically describing the echocardiographic assessment of the right ventricle, mainly focusing on the most useful parameters and the time of examination. The RV direct involvement happens quite often due to preferential lung tropism of COVID-19 infection, which is responsible for an interstitial pneumonia characterized also by pulmonary hypoxic vasoconstriction (and thus an RV afterload increase), often evolving in acute respiratory distress syndrome (ARDS). The indirect RV involvement may be due to the systemic inflammatory activation, caused by COVID-19, which may affect the overall cardiovascular system mainly by inducing an increase in troponin values and in the sympathetic tone and altering the volemic status (mainly by affecting renal function). Echocardiographic parameters, specifically focused on RV (dimensions and function) and pulmonary circulation (systolic pulmonary arterial pressures, RV wall thickness), are to be measured in a COVID-19 patient with respiratory failure and ARDS. They have been selected on the basis of their feasibility (that is easy to be measured, even in short time) and usefulness for clinical monitoring. It is advisable to measure the same parameters in the single patient (based also on the availability of valid acoustic windows) which are identified in the first examination and repeated in the following ones, to guarantee a reliable monitoring. Information gained from a clinically-guided echocardiographic assessment holds a clinical utility in the single patients when integrated with biohumoral data (indicating systemic activation), blood gas analysis (reflecting COVID-19-induced lung damage) and data on ongoing therapies (in primis ventilatory settings).
\end{abstract}

Keywords Right ventricle $\cdot$ Echocardiography $\cdot$ COVID-19 infection $\cdot$ ARDS $\cdot$ Ventilation

The Coronavirus disease 2019 (COVID-19) caused by the severe acute respiratory syndrome coronavirus (SARSCoV-2) was declared a pandemic in March 2020 by the World Health Organization [1].

The disease has a fatality rate which varies from less than $0.5 \%$ to more than $7 \%$, with an infectivity higher than influenza $[2,3]$. It is characterized by high trasmissibility and a sexual dismorphism, since elderly males with comorbidities are at higher risk of infection and death. In up to $15 \%$ of infected patients, the disease can evolve in a severe form of

Chiara Lazzeri

lazzeric@libero.it

1 Intensive Care Unit and Regional ECMO Referral Centre, Emergency Department, Azienda Ospedaliero-Universitaria Careggi, Largo Brambilla 1, 50134 Florence, Italy acute respiratory syndrome (ARDS) requiring mechanical ventilation and admission to intensive care unit (ICU).

The disease is systemic, though it has a lung tropism causing interstitial pneumonia, which can evolve in severe ARDS (Table 1).

Echocardiography has become a useful clinical tool both in medical wards and in critical care settings, since it is able to provide information on concomitant clinical conditions (i.e., heart failure) and on the current hemodynamic status and the heart-lung interactions. In the COVID-19 patients, the echocardiographic assessment of the right ventricle (RV) represents a pivotal element in the understanding of current disease status and in monitoring the disease progression.

The present manuscript is, therefore, aimed at specifically describing the echocardiographic assessment of the right ventricle, mainly focusing on the most useful parameters and the time of examination. An echocardiographic 
Table 1 Main parameters for RV assessment

\begin{tabular}{|c|c|}
\hline View & Normal values \\
\hline \multicolumn{2}{|l|}{ RV dimensions } \\
\hline RV-Focused four apical chamber view & $\begin{array}{l}\text { Base: }<41 \mathrm{~mm} \\
\text { Midlevel: }<35 \mathrm{~mm}\end{array}$ \\
\hline \multicolumn{2}{|l|}{ RV area } \\
\hline $\begin{array}{l}\text { Manual tracing of RV endocardial border from the lateral tricuspid annulus along the free wall to the apex and back to } \\
\text { medial tricuspid annulus, along the interventricular septum at end-diastole and at end-systole }\end{array}$ & $\begin{array}{l}\text { RV EDA indexed to } \\
\text { BSA }\left(\mathrm{cm}^{2} / \mathrm{m}^{2}\right) \\
\text { Men } \text { normal range } \\
5-12.6 \\
\text { Women normal range } \\
4.5-11.5 \\
\text { RV ESA indexed to } \\
\text { BSA }\left(\mathrm{cm}^{2} / \mathrm{m}^{2}\right) \\
\text { Men } \text { normal range } \\
2.0-7.4 \\
\text { Women normal range } \\
1.6-6.4\end{array}$ \\
\hline \multicolumn{2}{|l|}{ RV wall thickness } \\
\hline $\begin{array}{l}\text { Linear measurement of RV free wall thickness (end-diastole) below the tricuspid annulus at a distance approximating } \\
\text { the length of anterior tricuspid leaflet,fully open and parallel to the RV freewall }\end{array}$ & Normal value: $<5 \mathrm{~mm}$ \\
\hline \multicolumn{2}{|l|}{ TAPSE tricuspid annular plane systolic excursion } \\
\hline $\begin{array}{l}\text { Tricuspid annular longitudinal excursion (M-mode) is measured by proper alignmnt of M-mode cursor with the direc- } \\
\text { tion of RV longitudinal excursion from apical view }\end{array}$ & $\begin{array}{l}24 \pm 3.5 \mathrm{~mm} \\
\text { Abnormal }<15 \mathrm{~mm}\end{array}$ \\
\hline \multicolumn{2}{|l|}{ Right ventricle outflow tract acceleration time } \\
\hline By positioning the sample volume at the centre of the pulmonary artery (ideally at the annulus) in the short-axis view & Abnormal $<105 \mathrm{~ms}$ \\
\hline
\end{tabular}

$R V$ right ventricle, TAPSE tricuspid annular plane systolci excursion

examination in a COVID-19 patient should rely on "essential" measures that is measures easily feasible and reproducible, since it has to be performed quite in a short time to limit risk exposure and due to the uncomfortable protective equipment. Since few data are so far available in COVID-19 patients, some information has been translated from previous papers in ARDS patients $[4,5]$ and from our own experience in this field [6, 7].

Speckle tracking echocardiography is not discussed in the present paper, since it has been recently and extensively described [8]. Moreover, since this technique is time-consuming, it may not be feasible in COVID-19 patients in everyday clinical practice.

In the COVID-19 population, personal protection equipment of operators is crucial for the prevention of the widespread of the disease and staff protection, as well as the correct management of devices (i.e., echocardiographic machines) as stated by the ACC Clinical Bulletin COVID-19 Clinical Guidance for the CV Care Team [9]. It is imperative that devices, comprising ultrasound equipment, are cleaned and disinfected. Guidance on cleaning and disinfection procedures is also available online at the Centers for Disease Control and Prevention [10] and World Health Organization websites [11].

\section{Why an echocardiographic assessment should focus on the right ventricle in COVID-19 disease}

The right ventricle is directly and indirectly involved in the COVID-19 disease course.

The RV direct involvment happens quite often due to preferential lung tropism of the COVID-19 infection which is responsible for an interstitial pneumonia characterized also by pulmonary hypoxic vasoconstriction, and thus an RV afterload increase. Ventilatory therapy (non-invasive and invasive) affects RV dimension and function, by influencing heart-lung interactions.

The COVID-19 disease is responsible for a systemic inflammatory activation which may affect the overall cardiovascular system (including the RV) mainly by inducing an increase in troponin values, an increased in the sympathetic tone and altering the volemic status (chiefly by affecting renal function). 


\section{Technical issues}

\section{Transthoracic and/or transesophageal echocardiography}

The choice of the modality of echocardiograhy (transthoracic-TTE- vs. transesophageal-TEE-) is strictly related to the clinical conditions of the single patient as well as on the clinical inquiry. In mechanically ventilated patients, TEE is able to overcome technical problems with acoustic views, while in patients on spontaneous breathing and/or non-invasive ventilation, TTE is more feasible and it is able to answer most clinical inquiries.

\section{What to measure}

The following parameters, specifically focused on RV and pulmonary circulation, are to be measured in a COVID-19 patient with ARDS. They have been selected on the basis of their feasibility (that is easy to be measured, even in short time) and usefulness for clinical monitoring. It is advisable to measure the same parameters in the single patient (based also on the availability of valid acoustic windows) which are identified in the first examination and repeated in the following ones, to guarantee a reliable monitoring. Each measurement should be performed at least three times and a mean value should be considered.

(a) RV dimensions. Though RV size can be assessed visually by the "eyeball" method in the short-axis and 4-chamber views, it is advisable to quantitatively evaluate it by the ratio $\mathrm{RV} / \mathrm{LV}$ end-diastolic area. The $\mathrm{RV} / \mathrm{LV}$ area ratio is measured at end-diastole by tracing the areas of the two chambers in the apical four-chamber view on TTE or the mid-esophageal four-chamber view on TEE. In a RVfocused apical four-chamber view, RV dilatation is defined by a diameter $>41 \mathrm{~mm}$ at the base and $>35 \mathrm{~mm}$ at the midlevel [12]. In a series of one-hundred consecutive patients with COVID-19 infection, RV dilatation and dysfunction were a common finding, being detectable in the $39 \%$ and in the small subset of patients who clinically deteriorated (20\%), showed RV function deterioration [13].

(b) RV wall thickness. Its measurement is performed in diastole, from the subcostal view, using either M-mode or two-dimensional imaging. RV hypertrophy is identified by thickness more than $5 \mathrm{~mm}$ indicates. Whenever $\mathrm{RV}$ wall thickness $>5 \mathrm{~mm}$ is detected on ICU, it may indicate a chronic RV overload (previously unknown Chronic Obstructive Pulmonary Disease). In a mechanically ventilated patients, RV hypertrophy may be due to mechanical ventilation itself, since the right ventricle is known able to thicken in response to increased intrathoracic pressure [14]. (c) Systolic pulmonary arterial pressure. The RV right atrial pressure gradient can be estimated in presence of tricuspid regurgitation by measuring the peak regurgitant jet velocity (v) using continuous-wave Doppler echocardiography and the modified Bernoulli equation (RV systolic pressure $=4 v_{2}+$ right atrial pressure) [12]. In a retrospective study included in 112 COVID-19 patients, Deng et al. [15] reported an incidence of pulmonary hypertension of $13 \%$ but their series was constituted mainly by patients with mild COVID-19 disease. In a series of 28 patients with COVID19 disease requiring intensive care unit (ICU) admission, by means of serial echocardiograms, we observed that systolic pulmonary arterial pressures were increased in all patients on ICU admission but significantly decreased during ICU stay [16]. In a cohort of 200 patients with mild disease, those with pulmonary hypertension had signs of more severe COVID-19-related lung disease [16] and Szekely et al. [13] observed that patients with worse clinical grade had shorter pulmonary accelerating times suggesting increased RV afterload. In COVID-19-related ARDS, the development of increased systolic arterial pressures may be multi-factorial. First, hypoxic pulmonary vasoconstriction, known to characterize COVID-19-related ARDS [17], is probably the main factor. Second, lung disease (and progression) contributes to alterations in pulmonary circulation since atelectasia and consolidations exert mechanical compression of pulmonary vessels. Similarly, the role of pulmonary embolisms/thrombosis, not infrequent of COVID-19 disease, cannot be ruled out $[18,19]$. Finally, ventilations (specifically positive end expiratory pressure and driving pressures) are known to affect RV afterload. In this setting, the right ventricle has to face an augmented afterload, so it seems advisable to monitor pulmonary arterial pressure by means of echocardiography to early detect right ventricle dilatation and/dysfunction in these patients.

(d) Inferior vena cava diameter (IVC] and its collapse. In non-ventilated patients, it can be considered a good estimate of right atrial (RA) pressure. It is accepted that IVC diameter $<2.1 \mathrm{~cm}$ that collapses $>50 \%$ with a sniff suggests a normal RA pressure ( $3 \mathrm{~mm} \mathrm{Hg} \mathrm{mm} \mathrm{Hg}$ ), while an IVC diameter $>2.1 \mathrm{~cm}$ that collapses $<50 \%$ with a sniff suggests a high RA pressure of $15 \mathrm{~mm} \mathrm{Hg}$. In patients with RV dysfunction, the IVC collapsibility should be interpreted with caution and it should be considered also its trend and central venous pressure [12].

(e) Tricuspid lateral annular motion (tricuspid annular plane systolic excursion, TAPSE), an index of RV function. This parameter "captures" RV longitudinal motion and requires a proper alignment of M-mode cursor with the direction of RV longitudinal excursion from the apical view. Its main limitation is its angle dependence along with the concept that TAPSE is not representative of global RV function. Nevertheless, TAPSE showed a good 
correlation with RV fractional area change and radionuclide-derived RV ejection fraction [20]. RV dysfunction is indicated by a TAPSE less than $15 \mathrm{~mm}$ being associated with poor prognosis in critically ill patients [7].

In COVID-19-ARDS, inhaled nitric oxide (iNO) has been proposed as a rescue therapy in the recent guidelines [21]. In this context, serial echocardiograms could help in the early detection of worsening RV function and/or a further increase in systolic pulmonary arterial pressures, factors which may suggest a tempestive use of iNO.

(g) Left ventricle. A few key points. LV ejection fraction should be measured and clinically interpreted taking into account also the dosage of inotropic drugs if administered. Valvular diseases (mitral and aortic) should also be assessed, especially at first echocardiogram. The presence of valvular disease when at least moderate, is able to affect the course and severity of the lung disease and, obviously, therapies (especially fluid administration) [6].

When using TEE, the following parameters should also be measured: Superior vena cava collapse (absent or present), Filling pressures (low, normal, or high), Shunting across patent foramen ovale (absent or present).

Acute cor pulmonale (ACP). ACP is defined as the association of RV dilatation with a paradoxical septal motion at end-systole. In the era of protective ventilation, ACP is estimated to occur 20-25\% of ARDS patients, mainly related to plateau pressure, driving pressure and pCO2 $[4,5]$. "A so-called protective approach" was proposed based on the echocardiographic findings (mainly RV overload), to protect the right ventricle by setting/ adapting the ventilatory strategy. It mainly consists in decreasing the plateau pressure (below $27-28 \mathrm{~cm}$ of $\mathrm{H} 2 \mathrm{O}$ ), limiting the PEEP, avoiding intrinsic PEEP, and controlling hypercapnia. Whenever these adaptations are not feasible, the presence of ACP in refractory ARDS may suggest the use of extracorporeal membrane oxygenation support (ECMO) [4]. To date, ACP has not been reported in COVID-19-related ARDS, nor specifically addressed. Though protective ventilatory strategy is highly advised in COVID-19-related ARDS [21], each echocardiographic examination, especially in ventilated COVID-19 patients, should rule out/detect early signs of ACP and/or ACP development, in primis RV dilatation and the development of septal dyskinesia. In these circumstances, rescue therapies (such as iNO and/or ECMO) should be rapidly adopted. This is particularly true taking into account the high incidence of pulmonary embolism in COVID19 patients [22] due to COVID-19-related alteration in the haemostatic system [23]. In a series of 28 patients with COVID-19-related ARDS, ACP was detected in two patients (7\%), who required ECMO support [16].

\section{When to perform echocardiogram}

Echocardiography should be performed on admission in patients with COVID-19 disease and should be periodically repeated according to the clinical course. On admission, it is able to provide valuable information on the clinical status of that moment and to highlight clinical elements indicating previous diseases (i.e., ischemic heart disease and/or pre-existing chronic lung disease). If the clinical course is uneventful, echocardiograms should be done at least once a week and at discharge. In mechanically ventilated patients, it is advisable to perform an echocardiographic assessment at any time, higher ventilatory parameters are required to maintain adequate oxygenation or any new undifferentiated state of shock develops. Whenever RV dilation or dysfunction is detected (even at an echocardiogram performed routinely), treatments (ventilatory and not) should be re-examined and rescue therapies should be considered.

\section{Proning}

In COVID-19-related ARDS, proning is aften associated with amelioration of hypoxemia, though this maneuver may be more challenging in these patients, since accidental endotracheal tube disconnection from the ventilator may occur.

The greatest physiologic rationale for benefits from prone positioning can be found in those patients with more severe and heterogeneous lung injury and greater ventilation-perfusion heterogeneity in the dependent lung zones while supine. Placing a patient in the prone position facilitates recruitment and decreases heterogeneity of compliance, which improves oxygenation and minimizes injurious ventilation $[24,25]$.

So far, no data are available on the effects of prone position assessed by echocardiography on RV and pulmonary circulation. It can be hypothesized that whenever prone positioning is able to efficaciously treat ventilation-perfusion heterogeneity, a reduction in RV afterload (indicated by systolic pulmonary arterial pressure) could be detected at echocardiography performed after supination.

Information gained from a clinically-guided echocardiographic assessment holds a clinical utility in the single patients when integrated with biohumoral data (indicating systemic activation), blood gas analysis (reflecting COVID19-induced lung damage) and data on ongoing therapies (in primis ventilatory settings).

\section{Conclusion}

In COVID-19 patients, the clinical interpretation of echocardiographic findings specifically focused on RV dimension and function and on pulmonary circulation is complex since 
it should contemplate the assessment by disease severity (indicated by $\mathrm{P} / \mathrm{F}$ ratio and/or $\mathrm{PaO}_{2}$ ), the kind of ventilation (non-invasive vs. mechanical ventilation) and ventilatory parameters due to their influence on intrathoracic pressures.

According to available evidence [13,15-17], echocardiography should be part of the clinical evaluation of patients with COVID-19 infection, especially those with moderateto-severe disease. Indeed, RV dimension and function and systolic pulmonary arterial pressure are sensitive indicators of RV afterload, an indirect marker of lung disease severity in COVID-19 infection.

\section{References}

1. World Health Organization. WHO Director-General's opening remarks at the media briefing on COVID-19 - 11 March 2020. Available online at https://www.who.int/dg/speeches/detail/whodi rector-general-s-opening-remarks-at-the-media-briefing-on-covid -19-11-march-2020, (Accessed date: 4 Apr 2020).

2. Dong E, Du H, Gardner L (2020) An interactive web-based dashboard to track COVID-19 in real time. Lancet Infect Dis 3099(20):19-20

3. Zhang S, Diao MY, Yu W, Pei L, Lin Z, Chen D (2020) Estimation of the reproductive number of novel coronavirus (COVID-19) and theprobable outbreak size on the diamond princess cruise ship: adata-driven analysis. Int J Infect Dis 93:201-204

4. Zochios V, Parhar K, Tunnicliffe W, Roscoe A, Gao F (2017) The Right Ventriclein ARDS. Chest 152(1):181-193

5. Zochios V, Parhar K, Vieillard-Baron A (2018) Protecting the right ventricle in ARDS: the role of prone ventilation. J Cardiothorac Vasc Anesth 32(5):2248-2251

6. Lazzeri C, Cianchi G, Bonizzoli M, Batacchi S, Peris A, Gensini GF (2016) The potential role and limitations of echocardiography in acute respiratory distress syndrome. Ther Adv Respir Dis 10(2):136-148

7. Lazzeri C, Bonizzoli M, Cozzolino M, Verdi C, Cianchi G, Batacchi S, Franci A, Gensini GF, Peris A (2016) Serial measurements of troponin and echocardiography in patients with moderate-to-severe acute respiratory distress syndrome. J Crit Care 33:132-136

8. Lemarié J, Maigrat CH, Kimmoun A, Dumont N, Bollaert PE, Selton-Suty C, Gibot S, Huttin O (2020) Feasibility, reproducibility and diagnostic usefulness of right ventricular strain by 2-dimensional speckle-tracking echocardiography in ARDS patients: the ARD strain study. Ann Intensive Care 10(1):24. https ://doi.org/10.1186/s13613-020-0636-2

9. Mullen B. ACC clinical bulletin COVID-19 clinical guidance for the CV care team. https://www.acc.org/ /media/665AFA1E710 B4B3293138D14BE8D1213.pdf (Accessed March 8, 2020).

10. World Health Organization (WHO). Personal protective equipment. https://www.who.int/medical_devices/meddev_ppe/en/ (Accessed March 9, 2020).

11. Centers for Disease Control and Prevention (CDC). Protecting healthcare personnel. https://www.cdc.gov/hai/prevent/ppe.html (Accessed March 8, 2020).

12. Lang R, Badano LP, Mor-Avi V, Afilalo J, Armstrong A, Ernarnde L et al (2015) Recommendations for cardiac chamber quantification by echocardiography in adults: an update from the american society of echocardiography and the European association of cardiovascular imaging. J Am Soc Echocardiogr 28:1-39
13. Szekely Y, Lichter Y, Taieb P, Banai A, Hochstadt A, Merdler I, Gal Oz A, Rothschild E, Baruch G, Peri Y et al (2020) Spectrum of cardiac manifestations in COVID-19: a systematic echocardiographic study. Circulation 142(4):342-353

14. Vieillard-Baron A, Prin S, Chergui K, Dubourg O, Jardin F (2002) Echo-Doppler demonstration of acute cor pulmonale at the bedside in the medical intensive care unit. Am J Respir Crit Care Med 166(10):1310-1319

15. Deng Q, Hu B, Zhang Y, Wang H, Zhou X, Hu W et al (2020) Suspected myocardial injury in patients with COVID-19: Evidence from front-line clinical observation in Wuhan. China Int J Cardiol pii S0167-5273(20):31115-31123. https://doi.org/10.1016/j.ijcar d.2020.03.087

16. Lazzeri C, Bonizzoli M, Batacchi S, Cianchi G, Franci A, Fulceri GE, Peris A (2020) Cardiac involvment in COVID-19 -related acute respiratory distress syndrome. Am J Cardiol. https://doi. org/10.1016/j.amjcard.2020.07.010

17. Pagnesi M, Baldetti L, Beneduce A, Calvo F, Gramegna M, Pazzanese V, Ingallina G, Napolano A, Finazzi R, Ruggeri A et al (2020) Pulmonary hypertension and right ventricular involvement in hospitalised patients with COVID-19. Heart 106(17):1324-1331

18. Gattinoni L, Coppola S, Cressoni M, Busana M, Rossi S, Chiumello D (2020) Covid-19 Does Not Lead to a "Typical" acute respiratory distress syndrome. Am J Respir Crit Care Med 201(10):1299-1300

19. Manetta M, Coluccio V, Lippi M (2020) COVID-19, coagulopathy and venous thromboembolism: more questions than answers. Intern Emerg Med. https://doi.org/10.1007/s11739-020-02432-x

20. Kaul S, Tei C, Hopkins JM, Shah PM (1984) Assessment of right ventricular function using two-dimensional echocardiography. Am Heart J 107(3):526-531

21. Alhazzani W, Møller MH, Arabi YM, Loeb M, Gong MN, Fan E, Oczkowski S, Levy MM, Derde L, Dzierba A, Du B, Aboodi M, Wunsch H, Cecconi M, Koh Y, Chertow DS, Maitland K, Alshamsi F, Belley-Cote E, Greco M, Laundy M, Morgan JS, Kesecioglu J, McGeer A, Mermel L, Mammen MJ, Alexander PE, Arrington A, Centofanti JE, Citerio G, Baw B, Memish ZA, Hammond N, Hayden FG, Evans L, Rhodes A (2020) Surviving Sepsis Campaign: Guidelines on the Management of Critically Ill Adults with 2019 (COVID-19). Crit Care Med. https://doi.org/10.1097/ CCM.0000000000004363

22. Poissy J, Goutay J, Caplan M, Parmentier E, Duburcq T, Lassalle F, Jeanpierre E, Rauch A, Labreuche J, Susen S; Lille ICU Haemostasis COVID-19 group (2020) Pulmonary embolism in COVID-19 Patients: awareness of an increased prevalence. Circulation. https://doi.org/10.1161/CIRCULATIONAHA.120.047430

23. Cattaneo M, Bertinato EM, Birocchi S, Brizio C, Malavolta D, Manzoni M, Muscarella G, Orlandi M (2020) Pulmonary embolism or pulmonary thrombosis in COVID-19? Is the recommendation to use high-dose heparin for thromboprophylaxis justified? Thromb Haemost. https://doi.org/10.1055/s-0040-1712097

24. Munshi L, Del Sorbo L, Adhikari NKJ, Hodgson CL, Wunsch H, Meade MO, Uleryk E, Mancebo J, Pesenti A, Ranieri VM, Fan E (2017) Prone position for acute respiratory distress syndrome a systematic review and meta-analysis. Ann Am Thorac 14(4):S280-S288

25. Gattinoni L, Marini JJ, Pesenti A, Quintel M, Mancebo J, Brochard L (2016) The, "baby lung" became an adult. Intensive Care Med 42:663-673

Publisher's Note Springer Nature remains neutral with regard to jurisdictional claims in published maps and institutional affiliations. 